\title{
Erratum to: Selective PDE5A inhibition with sildenafil rescues left ventricular dysfunction, inflammatory immune response and cardiac remodeling in angiotensin II-induced heart failure in vivo
}

\author{
Dirk Westermann - Peter Moritz Becher • Diana Lindner • \\ Kostantinos Savvatis · Yu Xia • Matthias Fröhlich - Sebastian Hoffmann • \\ Heinz-Peter Schultheiss $\cdot$ Carsten Tschöpe
}

Published online: 25 January 2013

(c) Springer-Verlag Berlin Heidelberg 2013

Erratum to: Basic Res Cardiol (2012) 107:308

DOI 10.1007/s00395-012-0308-y

In Fig. 3 the representative image of $\mathrm{CD}_{11} \mathrm{~b}^{+}$immune cell staining of wildtype (WT) + sildenafil mice was mistakenly duplicated. Unfortunately, the representative image of the staining of the wildtype (WT) mice is missing. The correct representative histological image (red framed) is given below.

The online version of the original article can be found under doi:10.1007/s00395-012-0308-y.

D. Westermann $(\bowtie) \cdot$ P. M. Becher · D. Lindner .

K. Savvatis · Y. Xia · M. Fröhlich · S. Hoffmann .

H.-P. Schultheiss · C. Tschöpe

Department of Cardiology and Pneumology, Campus Benjamin

Franklin (CBF), Charité-Universitätsmedizin Berlin,

Hindenburgdamm 30, 12200 Berlin, Germany

e-mail: dirk.westermann@web.de

C. Tschöpe

Berlin-Brandenburg Center for Regenerative Therapies (BCRT),

Charité-Universitätsmedizin Berlin, Berlin, Germany

C. Tschöpe

DZHK (German Center for Cardiovascular Research),

Berlin, Germany 

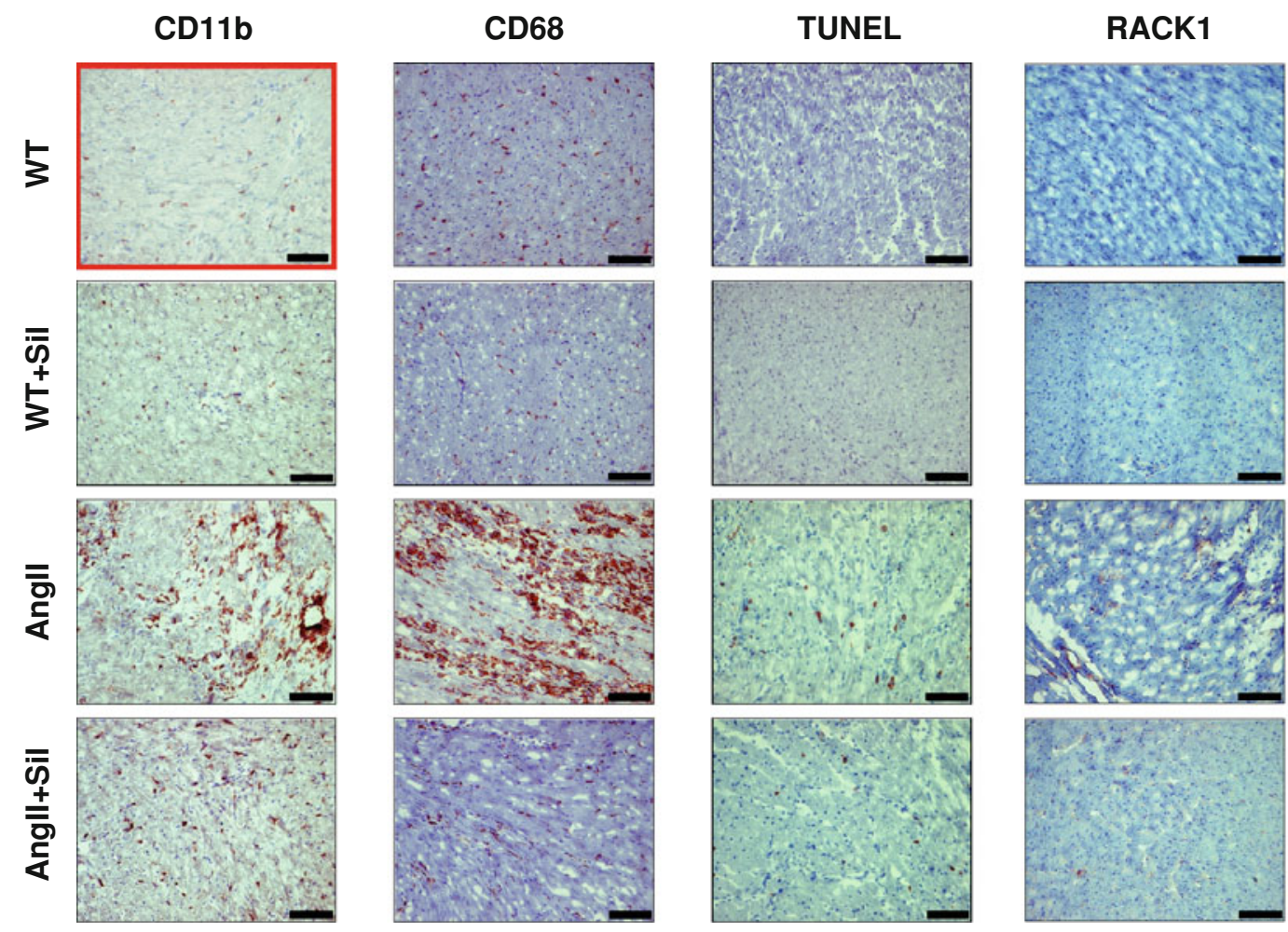

RAGE
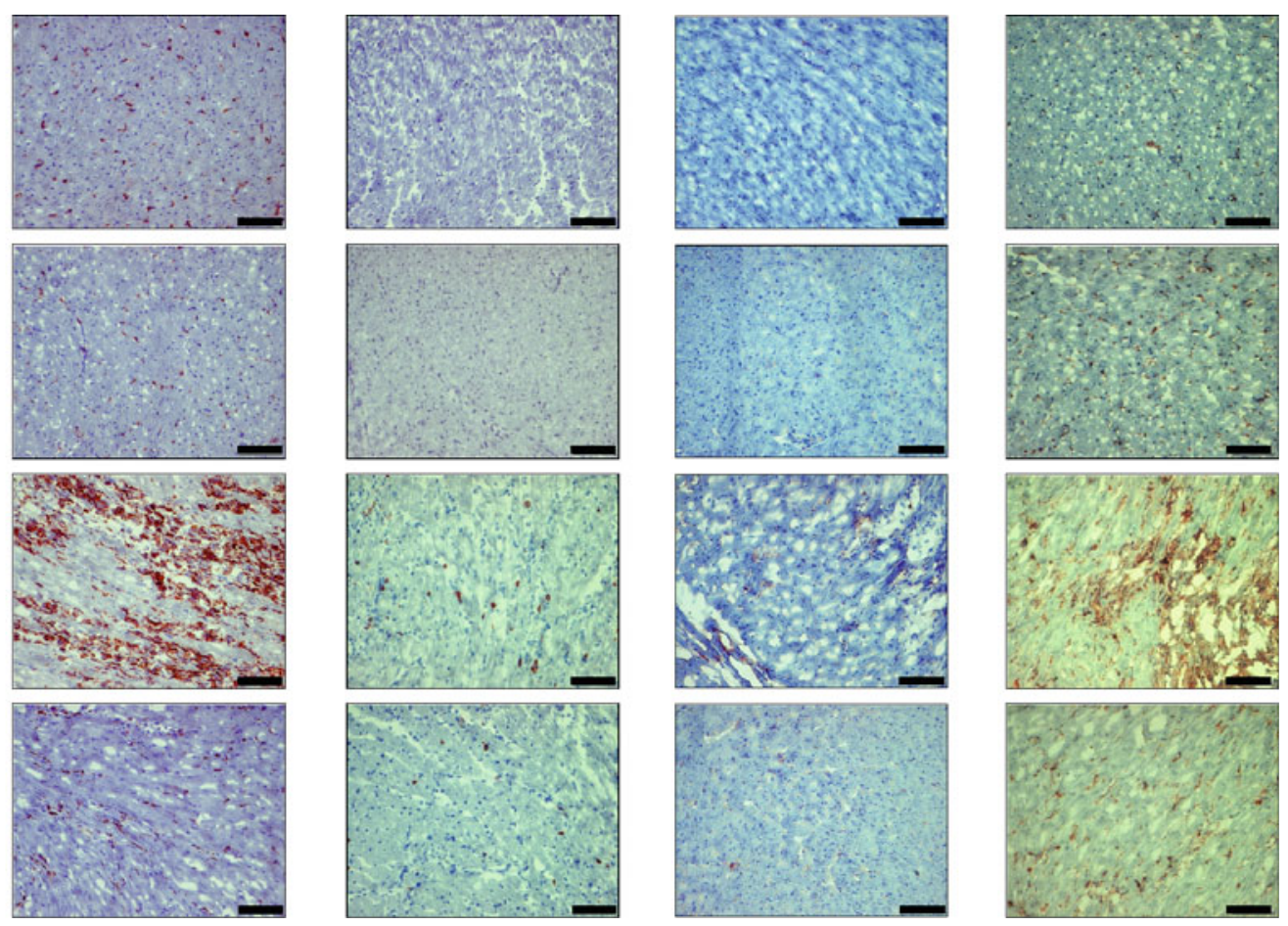